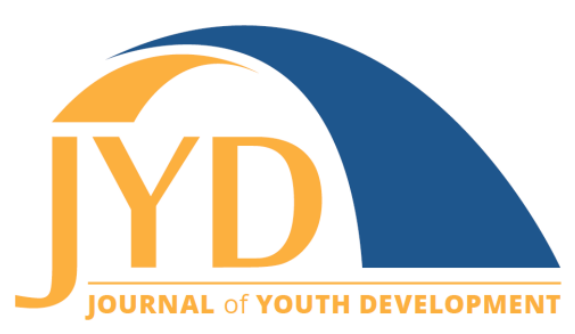

http://jyd.pitt.edu/ | Vol. 16 Issue 2-3 DOI 10.5195/jyd.2021.1054 | ISSN 2325-4017 (online)

\title{
Positive Youth Development in Senegal: A Case Study of 4-H Senegal
}

\section{Thomas Archibald}

Department of Agricultural, Leadership, and Community Education; Virginia Tech tgarch@vt.edu

\section{Bineta K. Guisse}

Feed the Future Senegal Youth in Agriculture, Virginia Tech

bguisse@vt.edu

\section{Amadou Ndiaye}

Université Gaston Berger

amadou.ndiaye@uam.edu.sn

\section{Fatimata Kane}

Department of Agricultural, Leadership, and Community Education; Virginia Tech fkane@vt.edu

\section{Fatou Diouf}

Feed the Future Senegal Youth in Agriculture, Virginia Tech

dfatou@vt.edu

\section{Kathleen Jamison}

Virginia Cooperative Extension

jamisonk@vt.edu

\begin{abstract}
African youth face great challenges and great opportunities. Positive youth development (PYD) programs have the potential to support youth in Africa to reach their full potential. Yet PYD approaches must be tailored if they are to be contextually and culturally responsive and relevant. The purpose of this paper is to provide an evidence-informed description of one such program, the 4-H Senegal PYD program. We first provide a conceptual background for the program, informed especially by the literature on global and cross-cultural PYD. We then share empirical results of a qualitative case study focused on the establishment, scale-up, and institutionalization of the 4-H Senegal program. Our case study results elucidate culturally responsive PYD program adaptations that corroborate conceptual framings of cross-
\end{abstract}

(cc) EY New articles in this journal are licensed under a Creative Commons Attribution 4.0 License. This journal is published by the University Library System, University of Pittsburgh and is cosponsored by the University of Pittsburgh Press. The Journal of Youth Development is the official peer-reviewed publication of the National Association of Extension 4-H Youth Development Professionals and the National AfterSchool Association. 


\section{Positive Youth Development in Senegal}

cultural PYD work while also pointing the way towards promising practice recommendations. We hope this conceptual and empirical summary of the 4-H Senegal program can contribute to the field by informing practice and guiding other innovative efforts to adapt PYD models and approaches across contextual and cultural bounds.

Key words: international positive youth development, Africa, Senegal, 4-H

\section{Introduction and Background}

African youth face great challenges and great opportunities. While the vast diversity of lived experiences among African youth makes it difficult to generalize about their condition, some of the most daunting challenges faced include poverty; food insecurity; illness; lack of access to quality education; un- and underemployment; civil unrest; and exclusionary local, national, and international policies (Nugent, 2005; United Nations, 2007).

On the other hand, African youth are key actors and agents of their own development; they are resilient, innovative, and intent on capitalizing on new opportunities presented by a constantly changing society (Hansen, 2008; Lo-oh, 2017). Young people across the continent create informal small businesses and other adaptive livelihoods, develop beneficial social networks, leverage technology, and engage civically to a greater extent than youth in the global North (Falola, 2004; Hansen, 2008). The intersection of opportunities and challenges in the lives of young Africans is complicated by differential context-specific realities dictated by region, country, religion, age, class, skin color, gender, and more.

According to the United Nations, it is "patently evident that engaging youth fully in sub-Saharan Africa's development is not a matter of choice, but rather an imperative for national development" (2007, p. 83). This is especially true due to the significance of the youth dividend in sub-Saharan Africa (SSA). In the next 3 decades, the youth population in SSA will continue to grow at a rate outpacing all other regions of the world. By 2050, SSA "will make up 33 percent of the world youth population, up from 19 percent in 2015. During this period, sub-Saharan Africa's youth population will increase by 522 million while the rest of the world's youth population declines by 220 million" (Wallace, 2019, p. 50). Reflective of this demographic dividend, in their adoption of the African Youth Charter in 2006, the African Union recognized that "Africa's future cannot be mapped out, and the African Union's mission fulfilled, without effectively addressing youth development, empowerment, and the preparation of young people for leadership and the fulfillment of their potential" (African Union, 2006, as cited in United Nations, 2007, p. 104). 


\section{Positive Youth Development in Senegal}

Unlike in the global North, there are relatively few institutional supports to facilitate African youths' transitions to adulthood. Positive youth development (PYD) is a set of principles and practices that emerged over the last 3 decades, largely in the global North, to empower youth to gain the life skills that will facilitate the realization of their potential (Hamilton \& Hamilton, 2004). This paper seeks to help bridge research and practice on the broad question of how to offer more and better PYD opportunities to youth in Africa, realizing that cross-cultural PYD approaches must be thoughtfully tailored if they are to be contextually responsive and relevant (Koller \& Verma, 2017).

As such, the purpose of this paper is to provide an evidence-informed description of one innovative PYD initiative in Africa, the 4-H Senegal PYD program. We first provide a conceptual background for the program, informed by literature on global and cross-cultural PYD. Then, we report empirical results of a qualitative case study of the program's establishment, scale-up, and institutionalization. We hope this conceptual and empirical summary of the 4-H Senegal program contributes to the field by informing practice and guiding other efforts to adapt PYD models and approaches across contextual and cultural bounds.

\section{Key Components of Positive Youth Development}

In general, the term youth development refers to three interconnected conceptual levels: a natural process of human development, a set of principles, and a range of practices (Hamilton et al., 2004). Positive youth development emphasizes life skills (Duerden et al., 2012;

Hendricks, 1998) and developmental assets (Scales et al., 2000). PYD is frequently discussed in terms of the "Five Cs" model focused on Competence, Confidence, Connection, Character, and Caring (Geldhof et al., 2015) and framed through the lens of relational developmental systems metatheory (Lerner \& Overton, 2008; Lerner et al., 2017).

PYD is often characterized by three notions. First, youth are resources to be developed, rather than problems to be managed (Jelicic et al., 2007; Roth \& Brooks-Gunn, 2003). Second, a problem-free youth is not necessarily fully prepared (Lerner \& Benson 2003; Pittman et al., 2000). Third, youth development occurs in community; PYD involves meaningful interactions between youth and their social environment (Bronfenbrenner, 1979/2009; Damon \& Gregory 2002). 


\section{Positive Youth Development in Senegal}

This socially-mediated, participatory nature of learning in PYD eschews the dominant discourse that "makes us think about the human mind as a container to be filled with certain materials and about the learner as becoming an owner of these materials" (Sfard, 1998, p. 5). This is the "banking concept" of education against which Freire positioned his pedagogy of "conscientization" (1970). In PYD, "youth are fully engaged participants, not just recipients" (Hamilton et al., 2004, p. 4). Especially in light of the many internal and external developmental assets that youth have, this Freirean, strengths-based, engaged pedagogy provides a wealth of resources that PYD can draw on to bolster youth success more intentionally.

\section{Positive Youth Development in Global Contexts}

As mentioned above, there are relatively few institutional supports to facilitate PYD for African youth. The dearth of PYD programming in Africa is problematic for both ethical and instrumental reasons. First, for ethical reasons, it is incumbent on development practitioners to facilitate dignified, sustainable livelihoods for youth everywhere, because everyone should have the right to not only meet their basic needs, but also to realize their fullest human potential. Second, for instrumental reasons, youth represent a significant leverage point; small positive changes youth effect now, when shared, multiplied, and exponentially applied over a generation, may be the most effective way to foster sustainable international development. Also from this instrumental perspective, especially considering global crises such as climate change (Sanson et al., 2018), there is a need to weigh the implicit opportunity cost of not interveninglarge populations of young people in the global South, if not supported and empowered via PYD programs to mitigate and adapt, risk experiencing disastrous outcomes, which in turn will exponentially exacerbate the toll of those crises.

Furthermore, when addressing PYD in Africa and elsewhere, the need remains to critically reflect on the cultural appropriateness of concepts, programs, practices, and policies exported from the global North. As Hutchinson pointed out, "Conventional Western pathways for researching young people have been guided by colonizing methodological and epistemological maps" (2002, p. 55). Nsamenang decried the Eurocentricity of adolescent psychology: "Western social scientists, for example, have demonstrated remarkable ethnocentrism and have, with few recent exceptions, presented their findings as relevant to the human race" (2002, p. 61). In response, he offered an ecocultural theory of social ontogenesis rooted in a West African paradigm, which "posits the growth of social selfhood through a series of phases, each characterized by a distinctive developmental task, defined within the framework of the culture's primarily socioaffective, developmental agenda" (Nsamenang, 2015, p. 841). 


\section{Positive Youth Development in Senegal}

Nuanced conceptualizations of constructs such as "youth" are important, since "youth assumes its meanings culturally and relationally rather than chronologically" (Hansen, 2008, p. 8). In Kenya for example, "Key productive assets are usually handed over only after marriage so defining youth by age becomes almost irrelevant" (Waldie \& Mulhall, 2002). To explain this phenomenon, Durham "combined the idea that youth is relational with the insight that invoking youth is a political, or pragmatic, act, to suggest that youth be treated as a social shifter" (2004, p. 589). That is, a term like "youth" indicates something that exists in the world independent of any particular use, yet also something that can only be understood when situated in context. The United Nations agrees, stating that youth "essentially represents the period of transition between childhood and adulthood, the nature and length of which vary from one individual or society to another" (United Nations, 2007, p. xxxvi). In the context of this paper, we consider youth as a life phase that overlaps with both childhood and adulthood, mediated by cultural influences and consisting of a plurality of developmental spheres, including cognitive, physical, social, and emotional (Eccles \& Gootman, 2002; Nsamenang, 2015).

In recent years, questions of cross-cultural and global PYD have been taken up with increasing frequency in the literature, including in books (Dimitrova, 2017; Petersen et al., 2016), special journal sections (Leman et al., 2017; Wiium \& Dimitrova, 2019), and methodologically-focused literature (Catalano et al., 2019; Drescher et al., 2018; Lerner et al., 2019; Scales et al., 2017; Tirrell et al. 2019). It is against this backdrop that the program presented in this case study4-H Senegal—was created and assessed.

\section{Methods}

In the remainder of this paper, we provide an evidence-informed description of 4-H Senegal, based on a qualitative case study of the establishment, scale-up, and institutionalization of the program. In particular, the study focused on contextual and cultural adaptations, informed by the theoretical literature reviewed above. This study is an example of what Stake (1995) called an intrinsic case study, due to our interest in understanding this particular case, even as we aspire to draw instrumental generalizable claims about broader phenomena (e.g., the practices of cross-cultural PYD adaptation). The goal of this case study is to accurately describe the program, using a variety of data sources and interpretive lenses, focusing especially on the question: What does the 4-H Senegal experience teach us about cultural adaptation of PYD models? We hope this program case study contributes to the field by informing practice and guiding other efforts to adapt PYD models and approaches across contexts and cultures. 


\section{Data Sources}

To obtain data on the 4-H Senegal case, we used document review, participant observation, a survey, and illustrative success case stories informed by the Success Case Method (Brinkerhoff, 2003) and the positive deviance approach (Zeitlin et al., 1990). The document review and participant observation were the primary source material for the detailed program description found in the next section. Documents included the project proposal, quarterly and annual reports, relevant USAID policy and programmatic guidance documents, and related notes and reports. All authors of this paper have a role in implementing the program, so participant observation consisted of active engagement in trainings, meetings, and other program activities, recorded via meeting and observational notes. The survey, which is brief and predominantly qualitative, was sent electronically via Qualtrics to all adult 4- $\mathrm{H}$ trainers and leaders $(n=394)$. The illustrative success case stories were gathered using an electronic form sent to a purposive sample of leaders of clubs known to be performing well.

As an interpretive intrinsic case study, our approach to maintaining quality of data and conclusions is guided by the qualitative notion of trustworthiness (Lincoln \& Guba, 1986; Stake, 1995), which we implemented by drawing on multiple data sources and perspectives to seek triangulation and consensus. This study was reviewed by the Virginia Tech Human Research Protection Program (IRB \#20-771) and determined to not be human subjects research as defined by Health and Human Services and Food and Drug Administration regulations.

\section{Results}

\section{Description of the Program}

In the United States, $4-\mathrm{H}$ is the youth development program of the national Cooperative Extension Service, supported in part by the National Institute of Food and Agriculture (NIFA) through funding to the nation's land-grant universities; it has existed for over 100 years and, as the nation's largest youth development organization, serves over 6 million youth (Arnold \& Gagnon, 2020; 4-H, n.d.). 4-H in the United States emphasizes life skills, the essential elements (of belonging, mastery, independence, and generosity), caring adult relationships, and experiential and hands-on learning (Arnold \& Silliman, 2017).

4-H Senegal is a PYD program established in Senegal since 2015, housed within the Ministry of Higher Education, Research, and Innovation, led by the Feed the Future Senegal Youth in 


\section{Positive Youth Development in Senegal}

Agriculture (Jeunesse en Agriculture) project, which is implemented by the Center for International Research, Education, and Development at Virginia Tech and supported by the U.S. Agency for International Development Senegal mission (USAID/Senegal). Before providing more detail on the program itself, we first offer some document-based data on its context.

Like most developing countries, youth constitute the largest demographic of Senegalese society, simultaneously representing an impending threat and an immense opportunity. According to the most recent available statistics from Senegal's National Agency of Statistics and Demography (Agence Nationale de la Statistique et de la Démographie [ANSD], 2016), 69.7\% of the population is under the age of 30, with a median age of 18 (p. 37). About half of these youth live in rural areas. Senegal experiences higher rates of youth unemployment as compared to many other West African countries, estimated at nearly 32\% (Agence Nationale pour la Promotion de L'Emploi des Jeunes, 2016). Roughly $60 \%$ of all unemployed people in Senegal are under the age of 26 (ANSD, 2016).

In Senegal, the national economic development plan is presented in the Plan Senegal Emergent (PSE; 2014), which also informs USAID/Senegal's Country Development Cooperation Strategy. The first sentence of the PSE refers to the demographic context of Senegal: "Senegal is experiencing a strong momentum of population growth, while the supply of social services and the opportunities for integration into the labor market are very limited, particularly for the young population" (PSE, 2014, p. 1). The PSE reiterates the notion of youth as threat and opportunity: "The problem of training and employment is an acute one for the youth, but it is also a window of opportunity in terms of demographic dividends to support development efforts" (PSE, p. 8).

The USAID/Senegal economic growth strategic plan synthesizes these guiding documents, also reflecting USAID's (2012) Youth in Development Policy. USAID/Senegal emphasizes the role of PYD along with youth employment, entrepreneurship, and market-based vocational training in Senegal's economic and community development. In keeping with the strength-based approach of PYD, USAID/Senegal prioritizes youth engagement: programs should "build the four domains of youth assets, youth agency, youth leadership and participation and a strong youth enabling environment at the family, community and national levels" (USAID/Senegal, 2017, p. 12). USAID defines PYD as development that "engages youth along with their families, communities and/or governments so that youth are empowered to reach their full potential. PYD approaches build skills, assets and competencies; foster healthy relationships; strengthen the environment; and transform systems" (Hinson et al., 2016; McCabe, 2017). These guiding documents-along 


\section{Positive Youth Development in Senegal}

with others such as USAID's Systematic Review of Positive Youth Development Programs in Low-and Middle-Income Countries conducted by YouthPower Learning (Alvarado et al., 2017) informed the creation of 4-H Senegal.

\section{Origins and Early Days of 4-H Senegal}

The seeds of 4-H Senegal were planted in 2011 through an earlier Virginia Tech project, USAID/Education and Research in Agriculture (ERA), with support from Professor Ozzie Abaye. Then the 4-H Senegal program officially began as a formal ERA activity in March 2015 with an introductory training, in partnership with agricultural education, training, and research institutions (AETRs); Peace Corps; the national extension agency; and local non-governmental organizations (NGOs), leading to the creation of three pilot clubs around the town of Toubacouta in the region of Fatick: an adolescent club at a cultural center in Toubacouta, a community club in Santamba, and a primary school club in Ndoumbouji.

The training helped leaders and partners gain knowledge about PYD, life skills, and the 4-H model, emphasizing the importance of belonging, mastery, independence, and generosity (Kress, 2004). Participants also created lesson plans. Following the training, the leaders (two per club) recruited youth into clubs. The year 2015 involved follow-up coaching and check-ins with the clubs to help them get established. The clubs began implementing activities, such as gardening, fundraising, and community beautification campaigns. In 2016, the program was scaled up to the areas of Saint Louis, Ziguinchor, and Bignona, beginning with a second round of leader trainings facilitated by project personnel plus Virginia Tech faculty and Virginia Cooperative Extension 4- $\mathrm{H}$ agents. This period saw the program increase to over 30 clubs with 86 adult leaders trained and more than 500 youth enrolled.

Trained volunteers (e.g., primary and secondary school teachers, local NGO staff, grassroots community leaders, etc.) lead the local implementation at the club level, with backstopping from project staff and AETR faculty. Volunteer adult leaders create and run clubs, with youth ranging in age from 8 to 29, with a ratio of one adult leader to 15 youth. Club membership is voluntary; youth are informed about the opportunity and then decide to join or not. The program has developed an inclusion strategy, which is presented in the training of volunteers, designed to help club leaders recruit, accommodate, and retain a diversity of youth membersacross various axes of diversity including age, gender, socio-economic status, linguistic background, level of formal education, and disability status. All clubs are expected to be at least $60 \%$ girls or young women, but to date that ratio is not consistently achieved. 


\section{Positive Youth Development in Senegal}

Adult leaders help the youth in the club establish a leadership structure, to promote youth voice, with a president, vice president, treasurer, and secretary. The club leaders and youth participants decide on the club's topical focus, such as gardening, crafts, raising animals, food processing, entrepreneurship, environmental conservation, etc. Some clubs choose one focal topic while others move from topic to topic based on youth interests and available resources. In a testimony to the youths' ability to creatively identify and leverage internal and external assets, clubs receive almost no financial or other material support from the project, yet many conduct resource-generating activities (e.g., raising and selling chickens), demonstrating ownership by local chapters and a path toward financial autonomy and sustainability.

\section{Scaling Up and Institutionalization of 4-H Senegal}

Since 2017, with the advent of the Feed the Future Senegal Youth in Agriculture project, we have further scaled up 4-H Senegal and are now institutionalizing it as a national PYD program that will be sustained by the Government of Senegal upon the completion of the USAIDsupported project in 2022. To do so, we created seven regional poles, housed at public universities, each of which has strong buy-in from university leadership and a management cell consisting of a regional facilitator, a pedagogical coordinator, and an administrative coordinator. Each pole interacts with a local consortium of government agencies, NGOs, private sector actors, and other stakeholders to run its local programs (i.e., trainings, coaching, and support for club functioning). There are now 561 trained adult leaders, 125 active clubs, and 1948 youth enrolled.

Nationally, the program is embedded within the Ministry of Higher Education, Research, and Innovation, where it benefits from linkages to national research institutes, the national virtual university, the office for the promotion of scientific culture, and more. Financially, regional pole functioning is supported via sub-awards from Virginia Tech, but a business plan is being created whereby public-private partnerships, university budgets, and additional grants and contracts will keep 4-H Senegal functioning. A private non-profit 4-H Senegal Association was also created to advocate for and promote the sustainability and financial health of the program. There is a community of practice focused on creation and adaptation of evidence-informed curricula in the area of science, technology, engineering, and math (STEM), including climate change, and a group of young leaders doing youth participatory action research and evaluation focused on culturally-responsive and decolonizing methodologies. 


\section{Survey and I/lustrative Success Case Story Data}

For the purposes of this paper, we elected to focus our survey data collection on adult volunteers. This builds on recent work by Homan (2017), who explored competencies needed by caring, adult volunteer club leaders in 4-H Ghana. In part due to disruptions to workflows and internet access caused by COVID-19, the response rate was low $(n=27,6.8 \%)$. Despite the likely positive response bias and associated limitations to representativeness, the data nevertheless meet the needs of this descriptive case study. Using a general inductive approach for analyzing qualitative evaluation data (Thomas, 2006), nested in the broader intrinsic case study (Stake, 1995), we derived concepts and themes both within and across survey items. In Table 1, we present the survey items and key emergent concepts and themes by survey item. The survey was conducted in French with responses translated into English by the research team.

Table 1. Response Concepts and Themes From the 4-H Senegal Adult Leader Survey

\begin{tabular}{|c|c|}
\hline Question & Response concepts and themes \\
\hline $\begin{array}{l}\text { In your own words, } \\
\text { what is } 4-\mathrm{H} \text { ? }\end{array}$ & $\begin{array}{l}\text { Core concepts: The } 4 \mathrm{Hs} \text { (head, heart, hands, health), PYD, life skills, } \\
\text { leadership, self-esteem, experiential learning, caring relationships } \\
\text { Outcomes: Responsible engaged citizenship, positive social change } \\
\text { Program foci: Natural resources, resilience, agriculture, gardening, } \\
\text { reforestation, livestock-raising, addressing food security }\end{array}$ \\
\hline $\begin{array}{l}\text { In your own words, } \\
\text { what is positive youth } \\
\text { development? }\end{array}$ & $\begin{array}{l}\text { Core Concepts: The } 4 \text { essential elements (belonging, mastery, independence, } \\
\text { generosity), honesty, honor, skills, humanity, empathy, sharing } \\
\text { Outcomes: Youth reach their full latent potential; able to resist negative } \\
\text { influences; active (not passive), able to "get by" in creative ways } \\
\text { Community development: Local community development, positive } \\
\text { socioeconomic and cultural transformation } \\
\text { A program, not a concept: Some respondents conflated PYD with the 4-H } \\
\text { program of the Feed the Future Senegal Jeunesse en Agriculture project }\end{array}$ \\
\hline $\begin{array}{l}\text { What were the } \\
\text { strengths of your } 4-\mathrm{H} \\
\text { training? }\end{array}$ & $\begin{array}{l}\text { Training format/experiences: Open-minded and friendly trainers, good blend } \\
\text { of theory and field observation, collaboration and teamwork, interactive and } \\
\text { co-created training with experiences of trainers and participants; consideration } \\
\text { of local context } \\
\text { Competencies gained: New skills and knowledge, ability to train others } \\
\text { Other outcomes: Self-confidence; a paradigm shift, changing traditional } \\
\text { mentalities; self-improvement }\end{array}$ \\
\hline
\end{tabular}


Table 1. (continued)

\begin{tabular}{|c|c|}
\hline Question & Response concepts and themes \\
\hline $\begin{array}{l}\text { How could your } 4-\mathrm{H} \\
\text { training have been } \\
\text { improved? }\end{array}$ & $\begin{array}{l}\text { Training format/experiences: More peer-to-peer learning with other local } \\
\text { leaders, more field experience and exchanges with youth, give trainers a } \\
\text { facilitation packet to guide their subsequent trainings, more follow-up, make } \\
\text { training more utilization-focused and applied, use more local experts without the } \\
\text { language barrier to save time. } \\
\text { Competencies needed: Proper use of USAID logos; leadership skills }\end{array}$ \\
\hline $\begin{array}{l}\text { What are the } \\
\text { strengths of your } \\
\text { current 4-H clubs? }\end{array}$ & $\begin{array}{l}\text { Core characteristics: Engagement, teamwork, sharing, solidarity, unity, } \\
\text { belonging, pragmatism, creativity, community service, long-term vision for club, } \\
\text { shared personal and professional vision (agricultural development), resilience in } \\
\text { face of daily realities, mastery of content }\end{array}$ \\
\hline $\begin{array}{l}\text { How could your } 4-\mathrm{H} \\
\text { clubs be improved? }\end{array}$ & $\begin{array}{l}\text { Training needed: Refresher PYD trainings and follow-up, training in agricultural } \\
\text { entrepreneurship and agribusiness, other tracks } \\
\text { Funding: For projects, transportation, material } \\
\text { Other programmatic needs: Collaboration, visits, exchange with other clubs } \\
\text { (national and international), institutional backup at AETRs }\end{array}$ \\
\hline $\begin{array}{l}\text { In what ways is the } \\
4-\mathrm{H} \text { model a good } \\
\text { fit for the } \\
\text { Senegalese } \\
\text { context? }\end{array}$ & $\begin{array}{l}\text { Core characteristics: Validating and valorizing informal education; unlike national } \\
\text { education which is distant and out of touch with cultural context; starting with } \\
\text { the realities and interests of the focal youth; response to marginalization of } \\
\text { youth, timidity; hands on, essential elements linked to traditional values } \\
\text { (sociocultural, religious, self-starter spirit, etc.) } \\
\text { Program foci: Addressing youth unemployment via entrepreneurship } \\
\text { community service; agricultural content } \\
\text { Suggestions for improvement: Add reproductive health; make into a regular } \\
\text { after-school program with school gardens }\end{array}$ \\
\hline $\begin{array}{l}\text { In what ways have } \\
\text { you had to adapt } \\
\text { the } 4-\mathrm{H} \text { model to } \\
\text { make it better fit } \\
\text { the Senegalese } \\
\text { context? }\end{array}$ & $\begin{array}{l}\text { Key practices: Use local language; experiential and practice-based learning; } \\
\text { engage parents and communities to raise awareness on 4-H; include adult } \\
\text { women and adults living with disabilities as participants; connect to local groups } \\
\text { and actors on projects (e.g., for reforestation, back-to-school kits, etc.) }\end{array}$ \\
\hline
\end{tabular}

Note. More frequently reported concepts are indicated in italics. 


\section{Positive Youth Development in Senegal}

For the illustrative success case stories, we highlight three clubs:

- Best of Us: This university club was created in January 2016 at Gaston Berger University in Saint Louis, in the north of Senegal. Its leader is El Hadji Kébé, a 28-yearold graduate student. It has 20 college student members (11 women, 9 men), ages 2130. Their main focus is personal development, with activities on public speaking, selfconfidence, and teamwork. The biggest challenge club members have faced is overcoming their shyness, which is one of the goals of the group. As they adapt PYD to their context (including the context of COVID-19), they have found success holding virtual activities and meetings via WhatsApp. As El Hadji says, 4-H is "a program that helps us go further, to develop life skills, and to be better."

- Jeunes Entrepreneurs au Cœur du Développement (Young Entrepreneurs at the Heart of Development): This club at an agricultural higher education institutethe Institut Supérieur de Formation Agricole et Rurale, part of Alioune Diop University of Bambey-was created in January 2017. It has two young leaders, Astou Tine (a 22-yearold woman) and Seydina Diop (a 23-year-old man). It has 12 college student members (6 women, 6 men), ages 20 to 27. Their main foci are community service (including agricultural education for local children, town clean-ups, etc.), reforestation, and personal development. Their agricultural outreach gives them a non-formal venue in which to practice the theoretical knowledge they gain through coursework, while also giving back to their community-the essential element of generosity. As they expect to have careers as extension and development leaders, they are acutely aware of the benefits of gaining leadership experience in 4-H while still students.

- Club Oignon (Onion Club): This club was launched in March 2016 at an agriculturaltechnical high school in the south of Senegal—the Lycée Technique Agricole Emile Badiane. With two adult leaders (Mrs. and Mr. Sane, both of whom work at the high school), the club has 15 members, ages 16 to 27. Activities include gardening and production horticulture, artisanal crafting, town clean-ups, and popular education theatre on topics like teen pregnancy prevention. The club sells fresh produce and crafts to generate revenue that they invest back into the club. According to Mrs. Sane, 4-H has made the youth engaged, hard-working, independent, and generous, with lots of selfesteem and a positive mindset.

\section{Discussion and Conclusion}

The results shared here provide a snapshot, however partial, of the 4- $\mathrm{H}$ Senegal program. This evidence-informed description, seen through the lens of the literature on global PYD, suggests a 


\section{Positive Youth Development in Senegal}

handful of key themes about cultural adaptation of PYD models that can be grouped as (a) continuities and similarities; (b) specific adaptations; and (c) avoiding cultural hegemony.

In terms of continuities and similarities, across document, survey, and success case data, there is evidence of the universality of many aspects of 4-H and PYD: Life skills, the essential elements, caring adult relationships, and experiential and hands-on learning are attributes that are just as present and as appreciated in Senegal as in PYD contexts in the United States. Youth have many of the same aspirations, dreams, strengths, and interests across varied contexts. Similarly, adult volunteers value open, collaborative trainings, reflecting the importance of adult education theories as a guiding frame for volunteer development. They seek frequent follow-up and continued professional development, as well as pedagogical supports to guide their work.

That said, there do appear to be specific ways in which 4-H Senegal has adapted PYD to the Senegalese context. One major way is the relative importance of applied community development actions, especially in agricultural and agribusiness applications. This reflects the data on un- and underemployment shared in the context section above, as well as the continued importance of agriculture as an element of the Senegalese economy. 4-H youth are making agriculture cool and framing it as a dignified and potentially lucrative career pursuit. The emphasis on community outreach partially parallels the generosity element of PYD in the United States, but in Senegal it takes on a special dynamic, as it intersects with traditional Senegalese cultural norms about service and community solidarity. This also reflects the "cando" attitude that is a characteristic of Senegalese culture, represented by the Wolof phrase, "Geum sa bopp." Additional adaptations include use of local languages (including the official language of French, the national language of Wolof, and regionally-specific languages as appropriate) and innovative leveraging of information and communication technologies (ICTs) such as WhatsApp, and an openness to taking on non-youth participants (e.g., people living with disabilities), new focal areas (like reproductive health), and new partners.

Reflecting on these similarities and differences, and juxtaposing the data with the theory and literature, this case study points to a handful of unanswered questions and directions for future work. For instance, there remains some question about the proper balance of and interaction between programming that is more focused on life skills and that which emphasizes more technical entrepreneurship and employment skills-both for 4-H Senegal and globally (including in the United States). Research shows that life skills and PYD may increase the success of youth employment programs (Fox \& Kaul, 2017), but this present study points to a need to further 


\section{Positive Youth Development in Senegal}

understand this complex dynamic in the case of Senegal. Also, this study does not provide sufficient insight into if and how 4-H Senegal successfully avoids cultural hegemony of the conventional colonizing methodological and epistemological pathways for youth work that Hutchinson (2002) and Nsamenang (2015) lament. 4-H Senegal may be mitigating this risk through use of local language, participatory and decolonizing research and evaluation, and prioritization of grassroots leaders and local sociocultural structures. But this is a question that requires more attention. In sum, we hope the lessons and reflections represented by the program description and empirical themes shared in this article can bridge research and practice to guide other efforts to adapt PYD models and approaches across contexts and cultures.

\section{Author Note}

This article is dedicated to the memory of Mor Seck. We also acknowledge and thank Ozzie Abaye and all the people who helped launch 4-H Senegal.

The program described in this article is made possible by the generous support of the American people through the United States Agency for International Development (USAID) as part of Feed the Future, the U.S. Government's global hunger and food security initiative, under the terms of Contract No. AID-685-LA-17-00002. The contents are the responsibility of the authors and do not necessarily reflect the views of USAID or the United States Government.

Amadou Ndiaye is now affiliated with Université Amadou Mahtar Mbow.

Declaration of interest: All authors are involved in the implementation of the project. The first and second authors are, respectively, the Director and National Director.

\section{References}

Agence Nationale de la Statistique et de la Démographie. (2016). Senegal in brief. http://www.ansd.sn/ Agence Nationale pour la Promotion de L'Emploi des Jeunes. (2016). Youth employment status (Presentation). Senegal.

Alvarado, G., Skinner, M., Plaut, D., Moss, C., Kapungu, C., and Reavley, N. (2017). A systematic review of positive youth development programs in low-and middle-income countries. YouthPower Learning, Making Cents International. 
Journal of Youth Development | http://jyd.pitt.edu/ | Vol. 16 Issue 2-3 DOI 10.5195/jyd.2021.1054

Positive Youth Development in Senegal

https://www.youthpower.org/sites/default/files/YouthPower/files/resources/SystematicReview\%2 OFINAL\%209-26-17\%20compress.pdf

Arnold, M. E., \& Gagnon, R. J. (2020). Positive youth development theory in practice: An update on the 4-H Thriving Model. Journal of Youth Development, 15(6), 1-23.

https://doi.org/10.5195/jyd.2020.954

Arnold, M. E., \& Silliman, B. (2017). From theory to practice: A critical review of positive youth development program frameworks. Journal of Youth Development, 12(2), 1-20. https://doi.org/10.5195/jyd.2017.17

Brinkerhoff, R. O. (2003). The success case method: Find out quickly what's working and what's not. Berrett-Koehler.

Bronfenbrenner, U. (2009). The ecology of human development. Harvard University Press. (Original work published 1979)

Catalano, R. F., Skinner, M. L., Alvarado, G., Kapungu, C., Reavley, N., Patton, G. C., Jessee, C., Plaut, D., Moss, C., Bennett, K., Sawyer, S. M., Sebany, M., Sexton, M., Olenik, C., \& Petroni, S. (2019). Positive youth development programs in low-and middle-income countries: A conceptual framework and systematic review of efficacy. Journal of Adolescent Health, 65(1), 15-31. https://doi.org/10.1016/j.jadohealth.2019.01.024

Damon, W., \& Gregory, A. (2002). Bringing in a new era in the field of youth development. In R. Lerner, F. Jacobs, and D. Wertlieb (Eds.), Handbook of applied developmental science (Vol. 1, pp. 407420). Wiley.

Dimitrova, R. (Ed.) (2017). Well-being of youth and emerging adults across cultures: Novel approaches and findings from Europe, Asia, Africa and America. Springer.

Drescher, C. F., Johnson, L. R., Kurz, A. S., Scales, P. C., \& Kiliho, R. P. (2018). A developmental assets approach in East Africa: Can Swahili measures capture adolescent strengths and supports?. Child \& Youth Care Forum, 471), 23-43. https://doi.org/10.1007/s10566-017-9415-0

Duerden, M. D., Witt, P. A., Fernandez, M., Bryant, M. J., \& Theriault, D. (2012). Measuring life skills: Standardizing the assessment of youth development indicators. Journal of youth development, 71 1), 99-117. https://doi.org/10.5195/jyd.2012.155

Durham, D. (2004). Disappearing youth: Youth as a social shifter in Botswana. American Ethnologist, $31(4), 589-605$.

Eccles, J. S., \& Gootman, J. (Eds.) (2002). Community programs to promote youth development. National Academy Press.

Falola, T. (2004). Teen life in Africa. Greenwood Press.

4-H. (n.d.). About 4-H. https://4-h.org/about/what-is-4-h/

Fox, L., \& Kaul, U. (2017). The evidence is in: How should youth employment programs in low-income countries be designed? (English; Policy Research working paper no. WPS 8500). World Bank 
Journal of Youth Development | http://jyd.pitt.edu/ | Vol. 16 Issue 2-3 DOI 10.5195/jyd.2021.1054

Positive Youth Development in Senegal

Group. http://documents.worldbank.org/curated/en/837861530219586540/The-evidence-is-inhow-should-youth-employment-programs-in-low-income-countries-be-designed

Freire, P. (1970). Pedagogy of the oppressed. (M. B. Ramos, trans.). Continuum.

Geldhof, G. J., Bowers, E. P., Mueller, M. K., Napolitano, C. M., Callina, K. S., Walsh, K. J., Lerner, J. V., \& Lerner, R. M. (2015). The five Cs model of positive youth development. In E. P. Bowers, G. J. Geldhof, S. K. Johnson, L. J. Hilliard, R. M. Hershberg, J. V. Lerner, \& R. M. Lerner (Eds.) Promoting positive youth development (pp. 161-186). Springer. https://doi.org/10.1007/978-3-319-17166-1 9

Hamilton S. F., Hamilton M. A., \& Pittman K. (2004). Principles for youth development. In S. F. Hamilton \& M. A. Hamilton (Eds.), The youth development handbook: Coming of age in American communities (3-22). Sage.

Hamilton, S. F., \& Hamilton M. A. (Eds.). (2004). The handbook of youth development: Coming of age in American communities. Sage.

Hansen, K. T. (2008) Youth and the city in the global south. Indiana University Press.

Hendricks, P. (1998). Targeting life skills model. http://www. extension.iastate.edu/4H/lifeskills/

Hinson, L., Kapungu, C., Jessee, C., Skinner, M., Bardini, M., \& Evans-Whipp, T. (2016). Measuring positive youth development toolkit: A guide for implementers of youth programs. YouthPower Learning, Making Cents International.

https://www.youthpower.org/sites/default/files/YouthPower/resources/PYD\%20Measurement\%2 0Toolkit\%20Final.pdf

Homan, D. (2017). Competencies and training needs of adult 4-H club leaders to facilitate positive youth development in Ghana, Africa. [Master's thesis, Ohio State University]. OhioLINK Electronic Theses \& Dissertations Center.

http://rave.ohiolink.edu/etdc/view?acc num=osu1492672937515349

Hutchinson, F. (2002). Cultural mapping and our children's futures: Decolonizing ways of learning and research. In J. Gidley \& S. Inayatullah (Eds.) Youth futures: Comparative research and transformative visions (pp. 53-65). Praeger.

Jelicic, H., Bobek, D. L., Phelps, E., Lerner, R. M., \& Lerner, J. V. (2007). Using positive youth development to predict contribution and risk behaviors in early adolescence: Findings from the first two waves of the 4-H Study of Positive Youth Development. International Journal of Behavioral Development, 31(3), 263-273. https://doi.org/10.1177/0165025407076439

Koller, S. H., \& Verma, S. (2017). Commentary on cross-cultural perspectives on positive youth development with implications for intervention research. Child Development, 88(4), 1178-1182. https://doi.org/10.1111/cdev.12873

Kress, C. (2004). The essential elements of 4-H Youth Development: Distillation to four elements. CSREES/USDA. 
Journal of Youth Development | http://jyd.pitt.edu/ | Vol. 16 Issue 2-3 DOI 10.5195/jyd.2021.1054

Positive Youth Development in Senegal

Leman, P. J., Smith, E. P., \& Petersen, A. C. (2017). Introduction to the special section of Child Development on positive youth development in diverse and global contexts. Child Development, 88(4), 1039-1044. https://doi.org/10.1111/cdev.12860

Lerner R. M. et al. (2017). Positive youth development among minority youth: A relational developmental systems model. In N. Cabrera \& B. Leyendecker (Eds.), Handbook on positive development of minority children and youth. Springer.

Lerner, R. M., \& Benson, P. L., (2003). Developmental assets and asset-building communities: Implications for research, policy, and practice (1 ${ }^{\text {st }}$ ed.). Springer US. https://doi.org/10.1007/9781-4615-0091-9

Lerner, R. M., \& Overton, W. F. (2008). Exemplifying the integrations of the relational developmental system: Synthesizing theory, research, and application to promote positive development and social justice. Journal of Adolescent Research, 23, 245-255.

\section{https://doi.org/10.1177/0743558408314385}

Lerner, R. M., Tirrell, J. M., Dowling, E. M., Geldhof, G. J., Gestsdóttir, S., Lerner, J. V., King, P. E., Williams, K., Iraheta, G., \& Sim, A. T. (2019). The end of the beginning: Evidence and absences studying positive youth development in a global context. Adolescent Research Review, 4(1), 114. https://doi.org/10.1007/s40894-018-0093-4

Lincoln, Y. S., \& Guba, E. G. (1986). But is it rigorous? Trustworthiness and authenticity in naturalistic evaluation. New Directions for Program Evaluation, 30, 73-84.

\section{https://onlinelibrary.wiley.com/doi/pdf/10.1002/ev.1427}

Lo-oh, J. L. (2017). Positive development in Africa. In L. M. Padilla-Walker \& L. J. Nelson (Eds.), Flourishing in emerging adulthood: Positive development during the third decade of life. Oxford University Press.

McCabe, M. (2017, June). Mainstreaming positive youth development for improved outcomes in ag training and education. Symposium conducted at the Innovate: AET Symposium, Washington, DC.

Nsamenang, A. B. (2002). Adolescence in sub-Saharan Africa: An image constructed from Africa's triple inheritance. In B. Brown, R. Larson, \& T. Saraswathi (Eds.), The world's youth: Adolescence in eight regions of the globe (pp. 61-105). Cambridge University Press.

Nsamenang, A. B. (2015). Ecocultural theories of development. International encyclopedia of the social and behavioral sciences (2 ${ }^{\text {nd }}$ ed. $), 6,838-844$. https://doi.org/10.1016/B978-0-08-097086$\underline{8.23205-4}$

Nugent, R. (2005). Youth in a global world. Population Reference Bureau.

Petersen, A. C., Koller, S. H., Motti-Stefanidi, F., \& Verma, S. (Eds.). (2016). Positive youth development in global contexts of social and economic change. Taylor \& Francis. 
Journal of Youth Development | http://jyd.pitt.edu/ | Vol. 16 Issue 2-3 DOI 10.5195/jyd.2021.1054

Positive Youth Development in Senegal

Pittman, K., Irby, M., \& Ferber, T. (2000). Unfinished business: Further reflections on a decade of promoting youth development. Youth Development: Issues, Challenges, and Directions (pp. 1764). Public/Private Ventures.

Plan Senegal Emergent. (2014). Republique du Senegal. https://www.sec.gouv.sn/sites/default/files/Plan\%20Senegal\%20Emergent 0.pdf

Roth, J. L., \& Brooks-Gunn, J. (2003). What exactly is a youth development program? Answers from research and practice. Applied Developmental Science, 72 ), 94-111. https://doi.org/10.1207/S1532480XADS0702 6

Sanson A. V., Wachs T. D., Koller S. H., \& Salmela-Aro K. (2018). Young people and climate change: The role of developmental science. In S. Verma \& A. Petersen (Eds.), Developmental science and sustainable development goals for children and youth. Social Indicators Research Series (Vol. 74). Springer. https://doi.org/10.1007/978-3-319-96592-5 6

Scales, P. C., Benson, P. L., Leffert, N., \& Blyth, D. A. (2000). Contribution of developmental assets to the prediction of thriving among adolescents. Applied Developmental Science, 4, 27-46. https://doi.org/10.1207/S1532480XADS0401 3

Scales, P. C., Roehlkepartain, E. C., \& Shramko, M. (2017). Aligning youth development theory, measurement, and practice across cultures and contexts: Lessons from use of the Developmental Assets Profile. Child Indicators Research, 10(4), 1145-1178. https://doi.org/10.1007/s12187-0169395-X

Sfard, A. (1998). On two metaphors for learning and the danger of choosing just one. Educational Researcher, 27(2), 4-13. https://doi.org/10.3102/0013189X027002004

Stake, R. (1995). The art of case study research. Sage.

Thomas, D. R. (2006). A general inductive approach for analyzing qualitative evaluation data. American Journal of Evaluation, 272), 237-246. https://doi.org/10.1177/1098214005283748

Tirrell, J. M., Dowling, E. M., Gansert, P., Buckingham, M., Wong, C. A., Suzuki, S., Naliaka, C., Kibbedi, P., Namurinda, E., Williams, K., Geldhof, G. J., Lerner, J. V., King, P. E., Sim, A. T. R., \& Lerner, R. M. (2019). Toward a measure for assessing features of effective youth development programs: Contextual safety and the "big three" components of positive youth development programs in Rwanda. Child \& Youth Care Forum, 49, 201-222. https://doi.org/10.1007/s10566019-09524-6

U.S. Agency for International Development. (2012). Youth in development policy: Realizing the demographic opportunity. Author.

U.S. Agency for International Development. (2017). Feed the future Senegal cultivating nutrition (RFA685-17-000007). Author.

United Nations. (2007). World youth report: Young people's transitions to adulthood: Progress and challenges. Author. 
Journal of Youth Development | http://jyd.pitt.edu/ | Vol. 16 Issue 2-3 DOI 10.5195/jyd.2021.1054

Positive Youth Development in Senegal

Waldie, K., \& Mulhall, A. (2002). Youth and rural livelihoods briefing paper 2: Kenya and Tanzania, IRDD. http://www.youthlivelihoods.info/resources.htm

Wallace, L. (2019). The urgency of securing employment for youth in Africa. In Harnessing Africa's youth dividend: A new approach for large-scale job creation. Brookings Institution. https://www.brookings.edu/wp-content/uploads/2019/01/BLS18234 BRO book 007 CH3.pdf

Wiium, N., \& Dimitrova, R. (2019). Positive youth development across cultures: Introduction to the special issue. Child Youth Care Forum, 48, 147-153. https://doi.org/10.1007/s10566-019-09488-7

Zeitlin, M., Ghassemi, H., \& Mansour, M. (1990). Positive deviance in child nutrition: With emphasis on psychosocial and behavioral aspects and implications for development. The United Nations University. 